Access to Justice in Eastern Europe,

Issue 4 (8) 2020

ISSN 2663-0575 (Print)

ISSN 2663-0583 (Online)

http://ajee-journal.com

10.33327/AJEE-18-3.4

C.H. van Rhee, E.A. Maan 'Civil

Procedure Reform: The Way Forward'

2020 4(8) Access to Justice in Eastern

Europe 180-208

10.33327/AJEE-18-3.4-a000035

\title{
CIVIL PROCEDURE REFORM: THE WAY FORWARD ${ }^{1^{*}}$
}

\author{
Prof. Dr. C.H. (Remco) van Rhee \\ Professor of Comparative Civil Procedure, Maastricht University, \\ Netherlands, Expert EU funded project Pravo-Justice
}

\section{E.A. Maan \\ Former President of the General Court of First Instance in Zwolle (1992-2006), Netherlands, Expert EU funded project Pravo-Justice}

Summary: 1. Introduction - 2. Implementation of the Civil and Commercial Procedural Codes in Ukraine: Findings and Observations. - 3. Conclusions and Key Recommendations. - Appendix: Questionnaires.

1 This article is based on C.H. van Rhee, E. Maan (co-author R. Kostur), 'Monitoring of Implementation of Civil and Commercial Procedural Codes. Final Report', prepared with the financial support of the European Union within the EU-funded Project PRAVO-Justice.

* Received: 21.10.2020. Revised: 06.11.2020. Approved: 24.11.2020.

(C) 2020 Access to Justice in Eastern Europe, C.H. van Rhee, E.A. Maan.

This work is licensed under a CC BY-NC 4.0 license.

This license allows reusers to distribute, remix, adapt, and build upon the material in any medium or format for noncommercial purposes only, and only so long as attribution is given to the creator. 
This article is based on a report evaluating the implementation of the new Ukrainian Civil and Commercial Procedural Codes. A multiple-choice questionnaire and an additional questionnaire for conducting in-depth interviews with selected stakeholders were used in order to collect data (see Appendix). This approach allowed for the identification of problematic areas in procedure and court organisation, for the collection and statistical elaboration of data on the implementation of the Codes, and for the identification of measures to improve court practice and organisation and, consequently, for enhancing trust in the judicial system.

For the purposes of the report, monitoring tools were complemented by court visits, bilateral interviews, and roundtables in different regions of Ukraine. These additional sources of information enabled the experts to develop informed observations on the specifics of the Codes and on the framework of their implementation. The research has resulted in a set of recommendations which are listed in the conclusion of this paper.

Keywords: Ukraine, Code of Civil Procedure, Code of Commercial Procedure, Civil Justice, Litigation, Courts, Evaluation.

\section{INTRODUCTION}

Authorities in Ukraine attach high importance to the new Civil and Commercial Procedural Codes and their proper implementation, aiming at the improvement of the functioning of the judiciary in civil and commercial cases and increasing trust in the judicial system. The objectives of procedural law reform in Ukraine are similar to the objectives of procedural law reform in other jurisdictions: improving the quality of the legislation (including access to justice and effectiveness of proceedings) and increasing the efficiency of proceedings (including cost-effectiveness, reasonable costs, and reducing the length of court proceedings). Instilling trust in the judicial system is another aim.

Within the context of the EU Project Pravo-Justice, a Procedural Codes Monitoring (PCM) mission was launched to analyse the implementation of the new Civil and Commercial Procedural Codes (new versions of these Codes were adopted in October 2017 and entered into force in December 2017). A selection of outcomes of the mission are presented in this article (see also the Appendix), and they can be used as a starting point for the introduction of the necessary practical measures to improve the implementation of the Codes and the identification of the actors involved in the implementation of such measures.

The experts have taken note of the outcomes of two other projects:

- The EU Twinning Project 'Strengthening the Institutional Capacity of the Supreme Court in the Field of Human Rights Protection at the National Level' executed by consultants from Germany, Austria, Latvia, and the Netherlands.

- A bilateral project between Ukraine and the Netherlands aimed at developing guidelines for court practice (see below).

Findings and ideas from these projects have also been incorporated in the present report. $^{2}$

2 Materials regarding these projects are in the possession of the authors and can be consulted on request. 


\section{IMPLEMENTATION OF THE CIVIL AND COMMERCIAL PROCEDURAL CODES IN UKRAINE: FINDINGS AND OBSERVATIONS}

Analysis of the implementation of the new Civil and Commercial Procedural Codes in Ukraine has led to a number of findings and recommendations, which concern such spheres as Human Resources, Legislation, Soft Law and Judicial Culture, Organisation, Working Conditions and Facilities, and the Bar. The analysis of each of these spheres is given in detail in this paper.

\subsection{Human Resources}

\section{Training for New Judges}

In Ukraine, those who want to become a judge are trained for a period of one year. It is questionable whether such a short training period is sufficient, especially for recently graduated candidates. In the Netherlands, it takes ca. 7 years between graduation and appointment as a judge. In France, the training of future magistrates takes almost four years after a severe selection process, whereas in England and Wales judges are mainly recruited from among experienced (usually 20 years or more) barristers. A longer training period than currently present in Ukraine would allow judges to acquire the necessary skills to administer justice, for example, where it concerns conducting hearings, attempts to settle cases, and presenting a proper analysis of the case to the parties. Improvement of skills will also foster more trust in the judiciary with the public at large.

\section{Continuous Training of Judges}

In Ukraine, continuous training is provided to judges on a tri-annual basis by the National School of Judges (10-day courses). Such training is without doubt useful, but the experts are of the opinion that the way training is organised should be amended.

In light of the introduction of the new Codes, it would be useful to organise focused and targeted training for all judges in order to ensure that they understand the new approach advocated by these Codes (more adversarial, less inquisitorial). Also, the new rules on disclosure require proper preparation. Unfortunately, no targeted courses were offered before the introduction of the Codes and, subsequently, the introduction suffered considerably.

Short (e.g. two days) and frequent (every four months) training sessions would be advisable. This would allow judges to focus on issues that prove to be problematic under the new legislation. Short training sessions at relatively short intervals allow judges to become familiar with the new rules and allow them to directly implement what they have learned. Training sessions should preferably be organised at the local and/or regional level, and they should also be open for attorneys, therefore, allowing interaction between attorneys and judges. Initially this may not be appreciated by Ukrainian judges, but experience in other advanced jurisdictions that have embraced the idea that litigation is the joint responsibility of all actors involved, has proven that interaction between judges and attorneys is beneficial. It creates common expectations 
and mutual understanding, which is very beneficial for the efficient administration of justice. It also creates trust in the justice system.

\section{Position and Remuneration of Judges}

The system of remuneration of judges should reflect the role the judiciary has to play within society. The new Codes aim at a thorough preparation of cases at first instance. On appeal, only facts established at first instance should be taken into consideration; new facts cannot be introduced. This means that litigation at first instance is central in the life of a lawsuit. Obviously, such an approach requires experienced and motivated first-instance judges. This can only be achieved if the career prospects and remuneration of judges are in line with their responsibilities. In this respect, the observation in the Twinning Report (see the introduction above) that a better quality of the first instance courts will lead to a lower number of appeals should be highlighted.

It is a serious concern that the present position of a judge is not very attractive at many courts and in various regions of Ukraine: unpleasant working conditions, the constant threat of disciplinary proceedings (see below), modest remuneration, understaffed courts, a high workload, and a negative image with the public at large are just a few circumstances that may not be attractive to many professionals.

\section{Staffing and Size of Courts}

The experts noted that the number of judges in the courts was frequently below the required number to execute all the necessary tasks. The Twinning report contains some statistics: the number of judges in the first instance courts is about $60 \%$ of the number that is needed; on appeal only $50 \%$ of the judges required to handle civil cases is present; and in the commercial appellate courts the number of judges is $71 \%$.

Introducing new Procedure Codes when courts are severely understaffed is not a good idea, to put it mildly. Understaffing is especially problematic when courts are relatively small, which is the case with many of the first instance courts in Ukraine. This makes these courts vulnerable in case of vacancies or illness, facilitates improper influencing of judges, does not allow for specialisation, and makes organising court work in a systematic way exceedingly difficult. Therefore, the merging of courts according to clear criteria would be helpful. The creation of general courts of first instance would be advisable, as is happening in many European jurisdictions, especially the most efficient ones. In the Netherlands, for example, such courts serve a population of ca. 1.5 million. The territorial jurisdiction of appellate courts in the Netherlands covers a population of ca. 5 million.

During interviews with stakeholders in Ukraine, it appeared that one of the (many) objections against larger courts concerns access to court and the visibility of the court system. This objection may be countered by creating central courthouses in the larger cities with trial centres in the region at a driving distance of, for example, about one hour from the central courthouse. On set days a selection of judges from the central courthouse would travel to the trial centres for hearings, and the local front office of the registry would facilitate their work. The suggested changes are of course major, but 
if Ukraine aims at a modern and well-organised court system, such changes cannot be omitted (examples of jurisdictions where this approach has been chosen are the Netherlands, Sweden, and England and Wales).

\section{Disciplinary Proceedings Against Judges}

Judges fear disciplinary proceedings being brought against them. In Ukraine, litigants bring disciplinary complaints frequently. This often occurs as part of procedural tactics or if they only disagree with the conclusions of the judge in their case. The fear for disciplinary proceedings makes judges feel restrained in the way they handle cases. As a result, they are not willing to use their discretionary powers to improve the way cases are litigated. The experts find it unusual that in cases like this disciplinary proceedings can be brought at all. They know that disciplinary proceedings are often abused in this way in Socialist systems where the Executive tries to control the Judiciary, but this should not happen in democratic, liberal societies.

It seems that the use of disciplinary complaints is rather widespread in Ukraine. In liberal, democratic societies, disciplinary proceedings should only aim at unacceptable behaviour of judges, e.g. where judges accept bribes or treat the litigants in a disrespectful manner. Such disciplinary proceedings are not meant to target the professional decisions of the judge in litigating cases. These decisions should only be subject to appeal and cassation. In situations where disciplinary proceedings are justified, one could consider measures to prevent abuse as much as possible. In the first place one could prescribe that attorneys, before they submit a disciplinary complaint against any judge, must have consulted the local Dean of the Bar and must state in their complaint that they have done so, mentioning the point of view of the Dean. In this way, the body in charge of overviewing the ethical behaviour of attorneys is informed about developments. Secondly, it would be advisable to have the president of the court handle small complaints and complaints that are clearly inadmissible (a complaint against the reasoning of the judge or against the decision itself) in order to deal with them within a short time-frame. Finally, requiring payment of a court fee for such complaints might be useful to prevent unmeritorious complaints. This fee should only be paid back when the complaint is wholly or partly successful. In this way, the fee would serve as a kind of fine for unmeritorious complaints.

\subsection{Legislation}

\section{International Developments}

One of the issues discussed at round tables and during interviews was that the new Ukrainian legislation is sometimes not in line with international developments in the area of civil and commercial procedure. ${ }^{3}$ During the last few decades, many European jurisdictions have introduced far-reaching reforms in civil procedure. These reforms

3 Here one should also refer to the ELI/UNIDROIT Model European Rules of Civil Procedure, which were recently approved by both institutions and which will be published soon. 
have several features in common. They put an emphasis on the obligations of the parties and their attorneys in preparing their case well before it is brought to court, and they reduce the number of motions that may be submitted in individual cases. Additionally, they provide the judge with the necessary case-management powers in conducting the lawsuit, and they aim at avoiding procedural complications. In Ukrainian legislation traces of these aims can also be found, but the experts feel that this is not always the case in actual court practice.

\section{Preparation of the Implementation of New Legislation}

Regarding the introduction and implementation of the new rules, the experts firstly find it remarkable that many respondents are not aware of an official document explaining the aims and purposes as well as the underlying principles of the new legislation. Secondly, the number of amendments to the draft legislation proposed by Parliament (apparently some 5,000 in total) is surprising. Such amendments, especially if introduced in great numbers, harm the consistency of the law as well as its clarity and structure. Parliament should concentrate on the great outlines of technical legislation and not on details. Details should be left to specialists in drafting legislation, as is the case in the majority of European jurisdictions. Thirdly, the time between the adoption of the Codes by Parliament and their entry into force was too short. This meant that those who have to work with the new legislation could not prepare themselves for the far-reaching changes that were introduced. It appeared to the experts that no or almost no training was offered to prepare for the implementation of the new Codes. It is, therefore, not a surprise that first experiences were difficult and sometimes confusing. The experts doubt that the new rules can be applied faithfully in practice. According to some respondents, the new rules are even ignored and judges continue hearing cases in the familiar manner from before the introduction of the new legislation (at several law schools it was stated that teaching had not been adapted to the new legal reality).

\section{Notification of Court Documents and Other Procedural Acts}

There are frequent problems with notification, which is surprising in an age of instant, electronic communication. The most fundamental solution to these problems would be transferring the responsibility for proper notification in civil and commercial litigation from the court to the parties. The parties should make use of the services of specialised private bailiffs for locating the opponent party and subsequent notification (private bailiffs have been introduced recently in Ukraine in addition to bailiffs employed by the state). The costs of notification should be borne by the parties and not by the court. This may be an incentive for parties involved in litigation to ensure notification in a costefficient manner by accepting documents and/or motions from the other party without formalities. Costs of notification are part of litigation costs and should in the end be borne by the losing party. Such costs should not be borne by the courts (as is currently the case) and this would result in a reduction of expenses incurred by the State.

Another, more practical approach to solve notification problems could be the following: notification is done as much as possible through electronic means, if possible, through 
the lawyer of the party that needs to be notified (lawyers should have a valid e-mail address for notification). If parties or their lawyer are not notified in the correct manner but nevertheless make an appearance in court, the right to claim that notification was defective is precluded. It is surprising that nothing of the kind has been considered when drafting the new Procedural Codes.

Citizens should, in the opinion of the experts, not be able to avoid notification. They should have an official address for notification, and notification should be valid if the citizen has been served at the correct address. This could be either a physical address or an electronic address.

The experts have the impression that often Ukrainian citizens are over-protected against rightful claims of creditors and that they have many possibilities to avoid being notified. This debtor-friendly approach is harmful for the economy. Debtors in need of protection should be protected by the State or society at large (social security measures), and not to the detriment of individual creditors who rightfully claim payment for services provided.

Related to this is the need to oblige courts to include the default interest rate (either starting from the submission of the claim or the date of the judgment) in judgements ordering the debtor to pay a certain amount of money.

\subsection{Soft Law and Judicial Culture}

\section{Practice Directions}

Not everything can be regulated by law. Additional rules and regulations will be necessary outside the Codes. Experience in other European jurisdictions shows that flexible, practical guidelines drafted by those who have to apply the rules (judges and attorneys) are often very successful. Regarding this topic, a project is currently being executed in Odessa, led by Judge Esther de Rooij, member of the board of the First Instance Court of Amsterdam. Three courts are participating in this project (the Court of Appeal of Odessa and the first instance courts of Malinovky and Izmaiel regions). Participants have agreed to draft two sets of guidelines/practice directions. One of these concern civil cases, while the other covers criminal litigation. The Ukrainian High Council of Judges has approved of the project and the Supreme Court has agreed to cooperate. It is expected that the project will continue for the next two years on the basis of a Matra-funded bilateral project (Ukraine and the Netherlands). The project deserves attention and support.

Guidelines may be the result of meetings of the leadership of the courts with the heads of the local or regional Bar Associations. At these meetings, the implementation of the rules from the Codes can be evaluated and solutions to the manifested problems can be agreed upon. These solutions should then become part of the guidelines. Of course, there should be transparency in organising meetings and drafting guidelines in the sense that interested persons have to be informed about the meetings, the agenda, and the participants beforehand. In such a way, the idea of a judicial network (consisting of, amongst others, representatives of clients, attorneys, court registries, courts, and enforcement agents) can be realised. 
Meetings and guidelines as mentioned above are absent in Ukraine. This is problematic, for example, as it results in an inflexible system and practices that may differ from one court to another.

\section{Disregarding the New Rules}

It seems that in Ukraine, the idea that new rules are capable of changing practice and behaviour is firmly believed in. Experience shows, however, that just changing the rules does not lead to a change in practice and behaviour. In order to introduce changes, the new rules need to be accompanied by measures facilitating their implementation.

An example of a change in the rules which has not resulted in a change in practice is the new procedural track for so-called 'minor cases' (i.e., small claims; Art. 278 and following Ukrainian Code of Civil Procedure). It is not often used since litigants prefer hearings, which are absent in this track. The many detailed rules on the minor cases track do not help to change this situation. A more straightforward approach would have been to lay down that cases under a certain value must be heard in summary proceedings unless the court decides otherwise (obviously, no appeal should be allowed against such a procedural decision). In addition to this rule, the legislature should create working circumstances for judges facilitating them to apply this rule strictly.

Another rule that is often ignored lays down that new facts cannot be introduced on appeal. There does not seem to be a consistent approach regarding this matter by the appellate courts. Some judges and lawyers stated that even the Supreme Court is too lenient regarding this matter. This results in a situation where first instance litigation is not taken seriously since the case can be litigated again on appeal. Parties not only have rights, but also (procedural) obligations and commitments; if they fail to comply with these, the court should draw the proper procedural consequences. The credibility of the system requires that the appellate courts maintain the rules strictly. They should make clear in the reasoning of their judgements that according to the applicable legislation, new facts cannot be introduced on appeal. It goes without saying that the Supreme Court has an important supervisory role in this respect.

Here, attention may also be paid to the order for payment procedure, which in its current form is not successful. This may be due to the fact that there are incentives for debtors in the current system to file opposition against orders for payment (which opposition then transforms the procedure in an ordinary lawsuit). Such incentives may be delays in the ordinary procedure and enforcement that allow them to postpone paying their debts.

\section{Judicial Discretion}

The experts have the impression that the new rules are sometimes very detailed, preventing judges from using discretion and dealing with cases according to their specific features. In a well-working justice system, one should give the professional judge sufficient trust to handle cases in the appropriate manner, using their expertise. Experts find support in the Twinning Report and argue that it is the role of the judge to understand the purpose of law in society and to help the law to achieve its purpose, bridging the gap between law and society. 
In general, the experts note that in Ukraine, much court time is being used for observing formalistic rules. An example is the rule that documents need to be summarised orally in a court hearing. The experts noted that the lawyers attending these hearings were not in a position to add much to the court proceedings apart from listening to the summary of the judge. Such wasteful use of court time should be prevented, if necessary, by the fiction that documents have been read aloud in court when they are listed in an inventory signed by the parties and the judge.

\section{Early Oral Hearing}

An early oral hearing where the case is discussed between the judge and the parties/ attorneys is beneficial for efficiency. Such a hearing could be scheduled after the statement of defence has been submitted. During this hearing, the judge and the parties/ attorneys could discuss whether the case can be settled and, if not, determine the further procedural steps that need to be taken. The judge could even decide that after this hearing, enough information has been obtained to decide the matter. The minutes of the hearing should detail what has been agreed upon. Hearings of this kind will also enhance trust in the judiciary. They are absent in Ukraine even though they would be possible under the current rules.

\subsection{Organisation}

\section{Specialisation}

The relatively small size of the courts in Ukraine does not allow for specialisation. This is not in line with current developments in other European jurisdictions, where specialisation is on the rise since it promotes efficiency and quality. This is not only true for family law, but also for other areas such as insolvency law. During interviews (see Appendix) it appeared that the absence of specialisation is problematic since civil judges often have to act as investigating judges in criminal cases. It appears that this hinders the daily work of civil judges, forcing them to postpone hearings in order to perform urgent tasks in the area of criminal law. In larger courts, it would not be necessary to hinder civil judges with the tasks of investigating judges and, as a result, their work in the civil section would move forward more smoothly without sudden interventions from other branches of the law. The experts do not feel that creating separate criminal courts would be beneficial since this would increase the costs of maintaining the courts and it would hinder relevant interactions between the judges of the civil and criminal divisions.

\section{Allocation of Cases}

Allocation of cases through a computer-programme aims at ensuring and enhancing the impartiality of Ukrainian judges. This is, however, only true in theory, since the system can be manipulated for various legitimate reasons by the person in charge of the system. It seems that parties are able to use the system in such a way as to ensure that their case is being heard by their preferred judge (e.g. by submitting the same case several times and withdrawing those cases that do not end up before the preferred judge, or by way 
of recusing the judge that is not preferred by a party). To improve this situation, it may be wise to allocate cases in a late stage of the proceedings, just before the first hearing, and to have the allocation of cases performed under the supervision of a senior judge on the basis of objective criteria, like the experience of the judge, their case load, and specialisation. Recusal should only be allowed on a limited number of grounds; here the introduction of a court fee for each motion to recuse should be considered, only to be returned when the recusal is successful.

\subsection{Working Conditions and Facilities}

\section{Working Conditions at the Courts}

Working conditions are often problematic at Ukrainian courts, at the civil courts more often than at the commercial courts. Facilities are insufficient (e.g. the experts were informed of judges having to pay for their own air-conditioning and electricity, buildings being decrepit without enough lightening, and offices being occupied by too many civil servants). Investments in the infrastructure of the courts is very much needed.

\section{Courthouses}

Courthouses need to show the ambition of courts to be institutions of authority that function independently and impartially. Courthouses should be well-located and divided in three sections: (1) proper waiting areas for the public, front offices, information desks, and courtrooms; (2) secure areas for detainees and investigating judges; (3) restricted areas with offices for the registry, supporting staff, and judges. After a security check, the public and lawyers should only have access to public areas. In this way judges and supporting staff will not be disturbed by members of the public entering their work spaces. At the same time the public is shown that judges are not accessible outside the courtroom and do only communicate with parties and lawyers in the courtroom in the presence of the opponent party. Courthouses in Ukraine often do not exhibit these features.

\section{Case Law}

The availability and accessibility of case law, mostly from the Supreme Court, belongs to the working conditions in court. Currently, the Ukrainian Supreme Court plans to improve the availability of its case law. The Twinning Report states: 'To get more legal unity and to make judgments more predictable it should help to provide the Supreme Court and the legal practice with a second public database. In this second database the Supreme Court can publish a subset of its judgments; only its guiding judgments or judgments in which the Supreme Court briefly provides the legal practice with an overview of its jurisprudence. Access to case law not only implies the technical possibility to consult court rulings, but also the possibility to identify relevant case law, something which may require editorial activity (as suggested in the Twinning Report) or sophisticated software. Moreover, case law and other relevant materials must be available free of charge, directly at the desk of the judge and the judicial assistants. 


\subsection{The Bar}

\section{Organisation}

The professional capacities and skills of attorneys as well as their mutual relationships are a matter of great concern. A well-functioning judiciary should, for example, be able to interact well with its most important partner, the Bar. Regular meetings should take place between the courts and the Bar in which practical issues can be discussed and resolved. This can lead to a more efficient procedure, but also to a better understanding by the various actors in lawsuits and prevent abuse of procedural tools. Moreover, practice directions and guidelines should be drafted with the input of the Bar. However, in the eyes of an important, well-educated group of Ukrainian attorneys, the position of the Ukrainian Bar is problematic. Considering the present situation in Ukraine, where the National Bar Association seems not to have the support and trust of a considerable number of lawyers, measures should be taken to ensure a representative Bar which can be a credible discussion partner for the judiciary.

The Twinning Report contains important information on the relationship of the various professional groups involved in the administration of justice:

'Judges, prosecutors and lawyers essentially contribute to justice in different roles. The interests of these professional groups are, naturally, different. Their work should be characterised by mutual professional respect. ... discussions with the various professional groups showed that their mutual relationships are very tense and complicated. While representatives of different legal professions deal with each other more objectively in most European countries, the interaction in Ukraine is marked by great mutual mistrust. This is detrimental to a case-oriented factual completion of the individual proceedings and should be countered by trust-building joint events and other measures.'

\section{Training}

Experts got the impression that training for attorneys is not well-organised by the Bar. Some law firms (usually the better ones) organise training themselves due to the questionable training offered by the Bar. Mandatory and focused training for attorneys, particularly where it concerns representing the interests of their clients in court, is very much needed. This would ensure that attorneys are also aware of the latest developments in legislation and case law.

\section{Fee System}

When discussing improvements of civil and commercial procedure, often fees are being mentioned by attorneys. It appears that attorneys have a financial interest in the number of motions and hearings. This can easily lead to proceedings which are not efficient. Measures are needed to take away incentives for inefficient litigation, which are not in the interest of the clients and which create a burden on the courts. Only necessary activities of the attorney should be remunerated. The court should evaluate whether activities have been in the interest of the client and clients should be informed about the strategy of the attorney and the related costs. 
Respondents often discuss the relationship between court rulings on costs and the remuneration as agreed upon between attorney and client. It should be mentioned here that for example in the Netherlands, cost rulings are only meant to calculate what the loser should pay the winner in compensation for costs incurred, but this calculation does not have to coincide with what the winner and their attorney have agreed upon as regards remuneration. In the Netherlands, the costs awarded by the court to the winner are usually less than the costs actually incurred by the winner. This is done on purpose because full compensation of costs may induce litigants to start litigation too easily. After all, at the start of a case, litigants often think that their case is much stronger than it appears to be in court when the opponent has also provided his/her arguments. The fact that the winner may have to pay part of the costs even if successful may make him/ her more careful when considering the start of litigation.

In the Netherlands, the National Bar Association publishes guidelines for costs to be agreed upon between client and attorney based on the type of case, the instance at which the case is being litigated (first instance, appeal, or cassation), and the number of relevant motions and hearings. The court does take these guidelines into consideration when determining the amount of costs to be paid by the loser.

\section{CONCLUSIONS AND KEY RECOMMENDATIONS}

The implementation of the new Civil and Commercial Procedural Codes in Ukraine meets various challenges and various measures are needed to improve the existing situation. The measures suggested in the present text are often not aimed at new legislation. It should be remembered that rules as such do not change practice. Changing practice is the result of interpreting and applying existing rules in the right manner, i.e. according to the aims the legislature had in mind when introducing the rules. In Ukraine, just like anywhere else, these aims include efficiency, effectiveness, and quality in the administration of justice. It is the task of the Supreme Court to show the lower courts the way ahead by providing interpretations in its case law that are uniform, clear, and well-reasoned. This presupposes a Supreme Court that has the time and facilities to execute this task and that is not overburdened with cases that are irrelevant for its main task. Filters to reduce the number of cases that reach the Supreme Cassation Court are in the opinion of the experts urgently needed.

The main recommendations that can be found in the report that served as the basis of this article (see footnote 1), can be divided in structural and practical recommendations. The main structural recommendations are as follows:

- Experts on organisational matters (not necessarily lawyers) should analyse the work processes in the Ukrainian courts. They should advise on how to optimise and standardise the work processes in court, from the moment a case is filed with the court until judgment and enforcement. This advice should be implemented in all courts, making work processes more uniform and efficient throughout Ukraine.

- Too many bodies are responsible for the judiciary. There should be a coordinator (a single person or a body of persons) for judicial affairs who oversees and coordinates measures and policies aimed at the courts. This 
coordinator could be the Ministry of Justice, the High Council for the Judiciary, or the Supreme Court.

- There are too many small courts in Ukraine. This hampers efficiency, uniformity and specialisation. A merger of courts is advisable, creating general courts for civil, commercial, administrative, and criminal matters, with sections devoted to each of these areas of the law. Courts serving a population of at least one million citizens would be advisable. Where needed, trial centres can be created where judges can sit for a limited number of days per month in order to guarantee that the administration of justice is sufficiently near the citizens in sparsely populated areas.

- When legislating on procedure and court organisation, judges and lawyers as well as court users should be involved, e.g. by way of internet consultations. In addition, legislation should not be introduced without sufficient preparation and training. This presupposes a sufficient period of time between adoption of the legislation and its actual entry into force.

- The allocation of cases to particular judges or panels of judges should be such that it can be influenced by neither litigants nor court staff. At the same time, the allocation system should be such that specialisation of judges in certain areas is being utilised. The allocation system should allow the burden of cases to be shared equally between the judges.

- Measures should be taken to make sure that the case law of the Supreme Court is easily available to all citizens. The case law should be presented in such a manner that it is searchable and that relevant case law can be identified easily. This also guarantees that the Supreme Court itself can guarantee the uniformity of its case law.

- Clear filters on the basis of objective (monetary) criteria for the admissibility of appeal and cassation should be introduced.

- Courts of appeal should not allow new facts on appeal.

- Measures should be taken to reduce the number of third-party interventions in civil and commercial proceedings.

- Parties should be allowed to agree on the territorially competent court; no referral to other courts in such cases.

- Further measures should be introduced to guarantee independence and impartiality of judges.

- One should make sure that the number of experienced judges in the first instance courts is sufficient.

- Remuneration and other working conditions should be reconsidered.

- A system of court-annexed mediation should be developed. Courts should refer to external, qualified mediators. Mediation should not take place in court. Judges should limit themselves to settlement attempts.

- Soft law (practice directions) should be used to guide the participants in the procedure. Judges should be involved in developing this soft law in order to make clear what the court expects from the litigants in areas not specifically regulated by law. Ideally, these practice directions should be uniform throughout the country.

- Where possible, the best European practices should be studied, made available, and used as an example in law reform. 
The main practical recommendations are as follows:

- An early oral hearing is beneficial for efficiency if used for settlement or setting a procedural calendar (discussing what is needed in the case). This requires an exchange of information between judge and parties (cards-on-the-table) and shared responsibilities. A cooperative attitude should be reflected by the lay-out of the courtroom: parties should not face each other but the judge.

- Precious court time should not be wasted by reading judgments in court. Judgments should be made available at the earliest possible moment in writing.

- Hearings should be used for exchanging information. The time available for the hearings should be communicated in advance (e.g. 20 mins per party). Hearings during which no exchange of information takes place are superfluous and a waste of time and money.

- Judges should ask questions during a hearing and should not use these hearings for long monologues.

- Court fees should be levied in all cases (including challenges of independence and impartiality and for filing disciplinary complaints) and should only be returned in exceptional situations. The amount of court fees should be such that they make parties consider the seriousness of their claim. When a service is free of charge, it is overused and abused.

- A quick and efficient procedure for dismissing unmeritorious claims should be developed.

- Clear-cut criteria should be developed in order to determine whether a case should be classified as minor (small claims). Subjective criteria like the importance of the case for the litigants should be abolished. Appeal and cassation in minor cases should not be possible. Ways to avoid the minor cases track after a case has been classified as minor should not be available.

- Judges should only be involved in real cases (judges should decide cases). Administrative work and clearly unfounded and vexatious claims should, as much as possible, be handled by legal support staff.

- Lawyers' fees are part of the contract between lawyers and clients. The court establishes these costs independently and not in relation to the agreement between lawyers and clients. The court follows set criteria. Obviously, when concluding their contract, lawyers and clients may take into consideration earlier court practice in similar cases. 


\section{APPENDIX: QUESTIONNAIRES}

\section{QUESTIONNAIRE A}

Questionnaire A was filled out by 278 respondents. The group of 278 respondents can be divided in the following sub-groups: Attorneys (163), Judges (47), Corporate lawyers (20), Legal scholars (14), Judicial assistants (1), Mediators (1), Court Secretaries (1), and Others (31).

\section{Chapter 1: Quality}

\section{Question 1: Aims}

1. The aims of the new Procedural Codes are enabling better access to court, proportionality, efficiency, low costs, and fairness. Do judges have these aims in mind when interpreting the procedural rules?

The number of respondents that answered this question positively without reservation is low (18.98\%). The largest number of respondents think it to be 'most likely' that judges have the aims of the Procedural Codes in mind when interpreting the new rules. Ca. 26\% of respondents think that judges do (probably) not have the relevant aims in mind.

\section{Questions 2, 3, and 13: Training}

2. Is additional training of judges needed in order to foster a better understanding of the procedural rules?

3. Is additional training of lawyers needed in order to foster a better understanding of the procedural rules?

13. Are the judges sufficiently trained in order to achieve the aims of the rules of procedure that are foreseen by the legislature?

The overwhelming majority of respondents (more than $85 \%$ ) is of the opinion that additional training is needed or most likely needed (even though ca. $67 \%$ of respondents are also of the opinion that judges are (most likely) sufficiently trained to achieve the aims of the procedural rules as foreseen by the legislature). This is not surprising given the fact that many respondents feel that sufficient training was not offered to them. Moreover, it seems that initial drafts were shared with the courts ca. 6 months before the introduction of the new legislation, but practising lawyers only obtained knowledge of the new legislation at the moment it was being introduced. Obviously, this is not effective and does not allow for preparation to ensure proper application. Those with an overly legalistic attitude to matters often forget that rules themselves do not change reality. It is the behaviour of those who apply the rules that has to be addressed. In many jurisdictions, important reforms in procedural legislation are often accompanied by training and other mechanisms to bring the reforms to the attention of those who need to implement these reforms in practice (judges and lawyers in our case), a very good example being England and Wales at the time of the important Woolf Reforms of 1998.

However, nothing of the kind seems to have been considered in Ukraine and this is unfortunate given the extent of the procedural reforms and their complexity. According to those interviewed by the experts, the Ukrainian process of legislation poses problems, also because in the Parliament large numbers of amendments are proposed that often do not support the coherence and clarity of the legislation. One should reconsider the role of individual members of the Parliament in drafting very technical legislation. In the majority of European jurisdictions, Parliament plays a far less dominant role regarding such matters than in Ukraine; often such work is done by specialised parliamentary commissions. For example, in England and Wales the 1998 Rules of Procedure were drafted by judges and other lawyers, a task that had been delegated to them by Parliament.

Question 4: Amending the rules

4. Will it be helpful to ensure that procedural rules are not frequently amended in order to allow judges and lawyers to find ways to improve legal proceedings in practice? 
Ca. $88 \%$ of respondents provided a positive answer to this question. Obviously, a stable procedural regulatory framework does not mean that improvements and changes cannot be introduced. Changes and improvements are also possible without changing the rules, for example based on the case law of the Supreme Court, or through agreements on the application of the rules within the judiciary, preferably after consultation with the Bar (judicial guidelines, practice directions, etc.). In most Western European jurisdictions, it has become clear that the procedural rules can only provide a framework for procedure and cannot regulate all aspects and practical details of it (this was already noted as regards codifications in general more than 200 years ago by JeanÉtienne Marie Portalis, the father of the French 1804 Code civil). ${ }^{4}$ In addition, rules, especially rules which come into being through the legislature, should not try to regulate every aspect of procedure since this prevents flexibility and the capability of judges to cope with the everyday problems in the administration of justice. The rules should set the framework in the context of which the judiciary has to operate, allowing the judiciary itself to do the necessary fine-tuning. An overly legislative approach to matters should be avoided at all means, since it labours under the erroneous belief that the rules themselves can change society, whereas in actual practice, change is an intricate interplay between the rules and those who apply them.

It has been observed by the experts that in Ukraine judges often perceive that they are not trusted by the authorities and the public at large. This results in a situation in which they are often not willing to direct court hearings in an efficient and effective way (using case management powers and skills) since they fear to be criticised. In order to change this, one may consider giving the judges instruments to direct court hearings efficiently and effectively, and allow courts to provide explanations to the public of the way the procedure is conducted. This calls for additional training of judges in order to further their forensic skills.

\section{Question 5: Orality}

5. Orality may increase the efficiency of the handling of cases in court. Is the level of orality sufficient in the procedural rules?

Ca. $70 \%$ of respondents feel that the level of orality is sufficient in the new procedural model. Ca. $27 \%$ of respondents feel that the level of orality is not sufficient. The latter number of ca. $27 \%$ may seem surprising given the high level of oral elements in the new Procedural Codes, but on second thoughts this may be explained by the fact that oral elements are not always used in an effective and efficient manner. An appearance of the parties and their lawyers before the judge should enable the judge to get a proper understanding of the dispute by asking relevant questions and by inviting parties to give their view on the matter that keeps them divided. Orality should not be used when it is neither effective nor efficient, and where writing - e.g. where it concerns statements of case, requests for interim decisions and documentary evidence - from the point of view of quality and consistency is a superior alternative. While attending court hearings in Ukraine, the experts noted that much court time is being used to go through court files, having judges dictate summaries of the materials for an audio registration in the presence of the parties and their lawyers without any oral interaction between a judge and parties/lawyers taking place. Obviously, such exercises can better be done in writing, for example in the final judgment where the judges have to give reasons for their judgment. Another option to avoid these time-consuming activities without added value could be disseminating a list of documents in the file to attorneys and agreeing that these are supposed to have been read out in court (legal fiction) although obviously in that case no audiorecording can be made (but, one should ask whether such a recording is really needed; who would consult the recording anyway?).

Also, the oral reading of full judgments should, in the opinion of the experts, be abolished as having no added value. Reading judgments in court is most likely a Soviet inheritance and it is utterly superfluous in times when everyone uses modern means of communication. An electronic message allowing those interested to read the judgment suffices. Such an approach to matters also

4 See Preliminary Address on the First Draft of the Civil Code, available at: $<$ https://www.justice.gc.ca/ eng/rp-pr/csj-sjc/ilp-pji/code/index.html> accessed 30 October 2020. 
guarantees publicity, and doing away with the reading of judgments in court allows the court to devote time to matters that really deserve attention.

It should be mentioned that some respondents argue that they prefer hearing the judgment being read straight after the hearing so that they know the outcome of the dispute right away. According to the experts, this apparently means that the written judgment that is read in court is not made available to the parties timely. It is suggested that this situation should be changed in the sense that a written text is made available as soon as possible, making the reading of the judgment superfluous in order to get timely notice of it (i.e. replace the reading of the judgment by providing the written text that is available at the moment originally set aside for reading).

\section{Questions 6, 7 and 8: Role of Case Law}

6. Does the system of case reporting (i.e. publishing case law) influence the behaviour of the parties when making decisions about taking cases to court?

7. Does the system of case reporting influence the parties when making decisions about the manner how to litigate cases?

\section{Does the system of case reporting influence the judges?}

Ca. $90 \%$ of respondents answer the above questions positively. This means that Ukraine has evolved tremendously since the times when case law did not play any role whatsoever, just like many Central and Eastern European states. It may indicate that lawyers inform their clients effectively about the relevant case law and that based on this information clients decide whether to go to court (although during the interviews it appeared that sometimes doubts exist as to the information the lawyers provide to their clients). It may also indicate that lawyers carefully consult case law in deciding how to litigate cases when brought to court. It furthermore indicates that judges take case law seriously. It should be mentioned here that the system of case reporting is still under development: the experts were shown a new database developed by the Supreme Court allowing interested actors to access it. Such initiatives are, obviously, very important. In presentday society, case law must be available to the public at large and free of charge.

\section{Question 9: Case Law and Uniformity}

Does the system of case reporting result in a more uniform application of the law throughout the country?

Ca. 75\% of respondents feel that the system of case reporting has a positive effect on the uniform application of the law throughout Ukraine. Again, this demonstrates that judges consult case law which influences their decisions, and that, in general, case law is taken seriously. This is a tremendous change when compared to previous practices and it shows that the new procedural rules are having a very positive effect according to those who apply and work with the rules. However, still more than $20 \%$ of the respondents finds that there is no unifying effect of case law.

\section{Questions 10 and 11: Case Law and Guidance to Judges}

10. Are the judges sufficiently aware of the case law of the cassation court?

11. Do the judgments of the cassation court provide sufficient guidance on how the highest court applies and interprets the law?

Ca. $78 \%$ of respondents are positive about the guiding effect of the judgments of the Supreme Court, whereas ca. $20 \%$ do not have a positive opinion. Ca. $73 \%$ of respondents believe that the judges are sufficiently aware of the case law of the Supreme Court. Ca. 18\% of respondents believe this is not the case. This is probably due to the fact that one is still experimenting with the case law of the cassation court to make it available through online platforms. Some judges interviewed by the experts indicated that they need to consult commercial publications in order to become aware of the relevant case law since the information provided by the cassation court itself was hard to navigate. Commercial publications would group relevant judgments together and would provide the necessary tools for a better understanding of the case law, whereas the online platform of 
the Supreme Court itself apparently only provides the case law without such tools. Some judges informed the experts that they did not have access or were not aware of the online platform of the cassation court, and that they had to pay prescriptions to commercial publications privately. The cassation court might consider developing better and systematic access to its case law.

This situation calls for developing a system to make case law available, not only for the judiciary but for the entirety of the legal community. Such a system should be searchable based on the relevancy of case law given the large number of cases that can be made available through electronic means.

\section{Question 12: Binding Precedents}

\section{What is the status of judgments of the cassation court?}

Surprisingly, there is no agreement as regards the status of the judgments of the cassation court between respondents. Ca. 35\% feel that the judgments are binding and need to be followed by lower judges, whereas ca. $48 \%$ regard these judgments as persuasive only. This means that the latter respondents are of the opinion that the situation in Ukraine is similar to that in many other civil law jurisdictions where a system of binding precedent does not exist. The ca. $35 \%$ of respondents who feel that the judgments of the cassation court are binding, seem to labour under the influence of common law jurisdictions, where indeed case law is binding and where elaborate systems of distinguishing exist when it is felt that in a particular case the relevant ruling of the Supreme Court should not be followed.

Since Ukraine is a civil law jurisdiction and systems of distinguishing are very labour-intensive, the experts would suggest that, like elsewhere in the civil law world, case law should be persuasive only, thus allowing judges to disagree with the rulings of the cassation court without distinguishing. This approach lays the burden of providing reasons why in a particular dispute case law should be or should not be followed on the cassation court and not on the lower judges (who should nevertheless, for reasons of transparency, explain why they chose not to follow case law that is apparently applicable to the case at hand). The cassation court will have to provide clear reasons when it feels that its case law is relevant for the case submitted to its court when quashing the decision of the lower court.

\section{Question 14: Procedural Tracks}

14. Does the differentiation between specific procedures for specific types of cases (civil, administrative, etc.) function well?

Ca. $48 \%$ of respondents believe procedural differentiation works well, whereas ca. $36 \%$ is of the opinion that this is not the case. The experts agree with the minority opinion that the new Codes are still somewhat static as regards the procedural tracks that are available. Especially the track for 'minor cases' (small claims; art. 274 CPC) is not being used frequently even though a large number of cases do in principle qualify for this track. It appears to be relatively easy to have 'minor cases' heard according to the track for regular cases. The problem seems to be that the track for 'minor cases' provides a completely written procedure, whereas judges feel that in many instances hearings are needed.

For the experts this does not come as a surprise, since a single hearing in a small and uncomplicated case may allow the judge to get a good grasp of the matter within a relatively short period of time, whereas purely written proceedings, as foreseen by the Ukrainian track for minor cases, have proven to be less effective. In actual practice, within many jurisdictions the purely written procedure is often prescribed for more complicated, technical matters in which hearings may not be particularly useful, whereas oral proceedings are often prescribed for uncomplicated matters. Whatever may be true, the experts believe that more flexibility in the rules, allowing judge and parties to decide what is the best procedural framework for the case at hand, may be the best approach to matters. This would mean that the judge and the parties discuss in an early stage of the procedure what is needed from a procedural perspective, that they agree on a procedural calendar, and that the calendar is used as guidance throughout the lawsuit. This approach is advocated in some Western European jurisdictions, notably in Sweden. 
It should also be mentioned here that many of those interviewed by the experts stated that the distinction between civil and administrative cases poses difficulties and results in interim judgments deciding on how to classify these cases.

\title{
Chapter 2: The Roles of the Parties and their Lawyers
}

\author{
Questions 15 and 16: Abuse of the Rules
}

15. Are the sanctions provided by the procedural rules against procedural misbehaviour effective?

16. Are changes needed in the rules against procedural misbehaviour?

Ca. $45 \%$ of respondents feel that the sanctions against procedural misbehaviour are most likely effective, and ca. $45 \%$ believe that this is (probably) not the case. Ca. $10 \%$ of respondents do not know whether this is the case. Therefore, it seems that a close look into this matter is needed because procedural misbehaviour is an old and persistent problem in litigation. Legal systems should provide sufficient means to stop such practice. Attention is especially required since ca. $63 \%$ of respondents feel that changes in the rules against procedural misbehaviour are needed.

\section{Question 17: Mandatory Representation and Quality}

17. Mandatory representation by a lawyer increases the quality of the court decision.

Ca. $64 \%$ of respondents feel this statement is true. Still, ca. $28 \%$ believe this statement is not true. This means that there is a need for research into this matter. Lawyers may obviously improve the quality of court decisions as one may expect them to filter out futile cases or cases that do not offer any prospects of success. Moreover, lawyers will know which documents are relevant for the file and will be able to produce them on time. An extremely adversarial attitude may not be helpful in this respect.

Since the new Ukrainian Codes advocate as a starting point an adversarial approach, one should pay close attention to the role of lawyers within this model. If the presence of lawyers does not increase the quality of court decisions, additional measures are needed (e.g. introducing a more cooperative model of litigation). Additional rules on training and education as well as rules on the admission to the Bar may prove to be necessary. Citizens must be able to rely on lawyers (and on their ability to give proper counsel) that have passed professional tests and that are able to instil confidence in clients that hire them to safeguard their vital interests. It should be noted that currently legislative measures pending before Parliament are aiming at abolishing mandatory legal representation in Ukraine.

\section{Questions 18, 19 and 20: Effects of Mandatory Representation}

18. Mandatory representation influences access to court.

19. Mandatory representation influences the efficiency of court proceedings.

\section{Mandatory representation influences fairness.}

Ca. 70\% of respondents believe that mandatory representation increases access to court. This is surprising, since mandatory representation obviously increases the costs of access to court for the parties, unless the legal aid system functions effectively or there are other means for people without the necessary financial means to engage a lawyer. It is suggested that research is conducted into the effects of mandatory representation on access to justice, especially from the perspective of costs and the legal aid system. Ca. $70 \%$ of respondents are also of the opinion that mandatory representation influences the efficiency of court proceedings, most likely in a positive manner since the judge can rely on trained lawyers when dealing with the case instead of on the parties themselves who obviously need a lot of judicial guidance when litigating on their own behalf. It would be relevant to understand how the general public, the clients of the attorneys, assess the work of their lawyers. A close look at the results learns that there is a conspicuous different 
opinion between judges and attorneys. For instance, 37\% of judges answer question 20 with yes, while $55 \%$ of attorneys answer this question positively.

Given the beneficial aspects of mandatory representation, it is surprising that only ca. $43 \%$ of respondents believe that it influences fairness: $\mathrm{ca}$. $47 \%$ of respondents believe that this is not the case. When it comes to efficiency (question 19), $80 \%$ of judges and attorneys think that mandatory representation is positive.

\section{Questions 21 and 22: Legal Aid}

\section{Is there a relation between the legal aid system and mandatory representation?}

22. Does the legal aid system guarantee sufficient access to court to underprivileged parties?

Ca. $51 \%$ of respondents believe that there is a relation between the legal aid system and mandatory representation, whereas ca. $20 \%$ do not believe that this is the case and ca. $28 \%$ do not know. This shows that many respondents do not have a clear view on the relationship between mandatory representation and access to justice. If access to justice is indeed an element of the right to a fair trial as appears from the Golder judgment of the European Court of Human Rights (Golder v. United Kingdom $),{ }^{5}$ all the respondents who are lawyers should have responded in the affirmative. In a situation where representation is mandatory, the legal system should provide means for indigent litigants to avail themselves of the help of a lawyer, either by way of a pro bono system, by way of paid legal aid, or by way of instruments like contingency fees (see also ECtHR Airey v. Ireland). ${ }^{6}$ Obviously, ca. $51 \%$ of respondents have noted the strong relationship between mandatory legal representation and legal aid, but it is alarming that ca. $20 \%$ have the opposite opinion, whereas a staggering ca. $28 \%$ do not know. Raising awareness about this matter among lawyers is obviously needed. This is also the case because ca. $27 \%$ of respondents feel that the legal aid system in Ukraine is not sufficient as it does not guarantee access to justice for underprivileged parties, and nearly $17 \%$ do not know whether this is the case. Once again, what was said above about the need for training, education, and admission to the profession shows the relevancy of this matter.

\section{Question 23: Access to Justice}

23. Can access to court for underprivileged parties be guaranteed by other means than legal aid (e.g. self-representation and assistance by the court of the party that does not have a lawyer)?

Ca. $50 \%$ of respondents feel that legal aid is the only means to guarantee access to justice to underprivileged parties. Ca. $43 \%$ feel that other means can (probably) also be used to guarantee access to justice to underprivileged parties. Again, this shows that a considerable number of respondents are not aware of the possibilities to provide access to justice without financial help of the State.

\section{Questions 24, 25 and 26: Preparation of Cases}

24. Are cases sufficiently prepared by the parties when they submit the case to the court?

25 . Are cases sufficiently prepared by lawyers when they submit the case to the court?

26. Are rules guiding the behaviour of the litigants and their lawyers before they go to court needed?

Only ca. $3 \%$ of respondents answer 'yes' without any reservations as regards the sufficient preparation by the parties before going to court. Ca. 50\% answer that cases are 'probably' sufficiently prepared by the parties. Ca. $40 \%$ of respondents feel that this is (probably) not the case. At the same time, the overwhelming majority of respondents feel that lawyers (probably) prepare cases well before going to court (ca. 85\%). This is unusual, since it is hard to see how a lawyer can be well-prepared while the client is not prepared, unless the questions were interpreted

$5 \quad$ Golderv. United Kingdom (App No 4451/70) ECHR 21 February 1975.

$6 \quad$ Airey v. Ireland (App No 6289/73) ECHR 9 October 1979. 
by the respondents in such a manner that preparation by litigants is only deemed relevant in cases where they are not represented by a lawyer.

The experts feel that further research into the issue of preparation is needed since an effective and efficient justice system is only feasible when parties and lawyers prepare their cases well before addressing the court. This is a joint responsibility. If problems exist (ca. $71 \%$ of respondents apparently feel that problems exist, because they advocate rules guiding the behaviour of judges and lawyers before they go to court), the English pre-action protocols may serve as an example; instruments such as these may be worthwhile for consideration in Ukraine.

A positive feature of these protocols is that before cases are brought to court, the parties and their lawyers investigate whether settlement is possible, and if this is not possible the case will be well-prepared when it is submitted to court. Obviously, also less stringent measures may be contemplated, such as a cards-on-the-table approach in the early stages of procedure including the presentation of evidence (Ukraine knows a cards-on-the-table approach, but it seems that this system is suffering from existing court practises, allowing evidence to be presented late without justification).

\section{Questions 27 and 28: Third Parties}

27. How does the system of admitting interested third parties to a pending procedure function?

28. How frequently are interested third parties admitted to a pending procedure?

Ca. $73 \%$ of respondents feel that the system of admitting interested third parties to a pending procedure works well. Ca. $63 \%$ of respondents are of the opinion that such parties are often admitted to pending procedures, whereas ca. $31 \%$ think that this happens sometimes.

The experts feel that in Ukraine third party interventions (interventions of others than the original parties to the suit) occur frequently. In other countries, this is rarely the case. Any intervention by a third party results in complications and more lengthy lawsuits, and, therefore, this matter should be evaluated critically. If necessary, the reasons and complications that may cause third party interventions must be removed.

\section{Chapter 3: The Role of the Court}

\section{Question 29: Case Allocation}

29. Is the current system of allocation of cases to particular judges sufficient?

Ca. $75 \%$ of respondents feel that the current system of case allocation is (probably) sufficient. Ca. $18 \%$ have doubts. According to the experts, the system of case allocation may be improved by allocating in a late stage, just before the first hearing is scheduled in order to prevent parties from contacting the judge. Obviously, judges should never convene privately with one of the parties outside the courtroom, but in order to make such encounters harder, a system of allocation which does not allow the parties to know who their judge is well in advance, may be beneficial. The experts also wonder how a system with a random allocation can be combined with the wish to have specialised judges hear cases dealing with the subject-matter in which they specialise.

During court visits and meetings with lawyers, it became clear that the manner of allocation in daily practice allows interventions that go against the professed ideal of random allocation (which aims at preventing all kinds of improper influence). This makes a system of random allocation problematic. In addition to late allocation (see above), it would be preferable to develop clear criteria for the allocation of cases (workload, illness, absence, other judicial/administrative duties, specialisation, work experience) and make these public. This would allow development of an informed and sophisticated system of case allocation instead of a system of random allocation with the help of a computer, a system which obviously causes all kinds of problems in practice and which is unknown in many European jurisdictions (Germany being an exception). 
30. Do the new rules foster independence of judges (undue external influence in decision-making is prevented)?

\section{Are additional measures needed to foster independence of judges?}

Ca. 57\% of respondents are of the opinion that the new Ukrainian rules foster the independence of judges. Ca. 34\% do (probably) not think that independence is being fostered by the new rules. This high number of ca. $34 \%$ is alarming according to the experts, also because more than ca. $80 \%$ of respondents are of the opinion that new measures fostering independence are (probably) needed. In addition, it seems that the trust of the public in the judiciary in Ukraine is rather low in comparison with European standards, so there is still work to do, also in terms of providing the general public with reliable information.

\section{Questions 31 and 33: Impartiality}

31. Do the new rules foster impartiality of judges (undue external influence in decision-making is prevented)?

\section{Are additional measures needed to foster impartiality of judges?}

Ca. $57 \%$ of respondents answer the first question positively. Ca. $34 \%$ is of the opinion that the new rules do not foster impartiality. The high number of ca. $34 \%$ is alarming according to the experts and the topic therefore urgently needs close attention, also because ca. $75 \%$ of respondents state that new measures fostering independence are (probably) needed.

\section{Questions 34 and 35: Trust and Discretion}

34. Should the judge be given more trust to implement the rules loyally?

35. Should the judge have discretion in organising court hearings?

Respondents seem equally divided as regards the trust to be given to judges when implementing the rules of procedure loyally: ca. $45 \%$ answer positively to this question, and ca. $51 \%$ negatively. Also, with regards the second question the picture is divided. Ca. $62 \%$ of respondents are in favour of discretion for the judge in organising court hearings and apparently consider judges capable of discretional decisions in this respect. Nevertheless, ca. 35\% of respondents express doubts or are not in favour of such liberty. This may imply that a considerable part of the respondents do not have enough trust in the professional capacities of the judges. It would be advisable to investigate whether this is true and to what extent, and to uncover the reasons for this possible lack of trust.

\section{Question 36: Hints}

36. Should the court be allowed to give an analysis of the possible manners in which the case may progress in court?

Allowing the judge to give an analysis of how the case may progress in court, especially in the early stages of the proceedings (such as during an initial hearing when the parties become aware of all aspects of their case), provides litigants with a tool to measure their chances of success. This tool may induce them to reassess their procedural position and to make the choice to settle their case early in order to avoid the risks, costs, and efforts related to court proceedings.

Ca. $70 \%$ of respondents are in favour of allowing the court to give an analysis and, since the rules of procedure do not prohibit the judge to do so, this might be an interesting case management instrument for the judge. In a conversation with parties and their lawyers, aspects dealing with obligations to produce evidence and the evidential risk (which party bears the risk if no sufficient evidence is brought forward) may lead parties to have a fresh look at threats and opportunities. Obviously, judges need training in this respect, e.g. in order to avoid giving the impression of partiality, and such training can be offered in cooperation with judges from jurisdictions where 
similar tools are being used. Moreover, this might require a change of procedural culture from the side of the attorneys as well; it even impacts on the relation between attorney and client.

\section{Question 37: Unrepresented Parties}

37. Are the answers to question 36 the same if a party is not represented by a lawyer?

Ca. $67 \%$ of respondents answer this question positively. In the opinion of the experts it is, however, not self-evident that the parties themselves, without the assistance of a lawyer, will be able to understand the analysis provided by the judge. If one wants to increase the likelihood of such understanding, it means that the judge should communicate with the parties in a non-technical manner, allowing parties to understand the implications of the information provided by the judge. The judges will have to be aware of the fact that they are not communicating with trained lawyers and must be able to express themselves in the appropriate manner. The experts feel that appropriate and focused training of judges is needed in this respect, although currently the relevance of this training may be limited due to mandatory representation by lawyers in civil and commercial disputes.

\section{Question 38: Passive Judge and Fairness}

38. The new rules assign the judge a relatively passive role. Does this result in a fair determination of the case?

The procedural system in Ukraine can be described as follows: a system in which the scope of the procedure is determined by the parties, where the parties have the primary responsibility to put forward what is relevant and to produce the relevant documents (evidence as well as other documents), and in which the judge is expected to ensure efficient and expedient litigation. The answers to the above question have to be evaluated from this perspective.

Ca. $50 \%$ of respondents answer this question positively, whereas ca. $44 \%$ answer the question negatively. This implies that a large minority of respondents are not convinced that the approach of the Ukrainian legislature which favours the adversarial system is correct especially where many other European jurisdictions - particularly where it concerns the role of the court as regards efficiency and speediness of proceedings - have turned away from adversarialism, introducing more cooperative models of litigation.

As is shown throughout history, adversarialism in its extreme form does not favour efficiency, effectiveness, and decisions that are based on facts that come near to the truth ('fair decisions'). Adversarial systems often allow the party with the most extensive financial means to win the case since the judge is passive and the lawyers do most of the work. Obviously, in such a situation the party with the best (usually most expensive) lawyers is likely to win the case. It is not without reason that in the US, with its extremely adversarial approach to litigation, the advice is to hire the best possible lawyer (i.e. the most expensive lawyer that one can afford) because one's chances to win the case will often increase significantly. This approach may not always result in fair decisions, i.e. decisions based on the true facts in which the party that is right indeed wins his case.

\section{Questions 39 and 40: Passive Judge, Efficiency and Reasonable Time}

39. The new rules assign to the judge a relatively passive role. Does this result in an efficient determination of the case?

40. The new rules assign to the judge a relatively passive role. Does this impact on the requirement of a hearing within a reasonable time?

Ca. $43 \%$ of respondents answer positively to the first question and ca. $50 \%$ answer negatively. So, there is no majority in favour of the idea that a passive judge increases efficiency. In the international debate on litigation, it is common wisdom that passive judges do not increase efficiency. Most modern legal systems have therefore introduced so-called case-management tools which allow the judge to guard over the time taken for litigation and, in some jurisdictions, even provide the judge with instruments to assist parties in the evidentiary stage of proceedings. 
Judicial case management guarantees that scarce resources are used in a careful manner and that litigation is not dependent on the whims of the parties. This approach guarantees that other cases that are waiting to be heard also get their day in court within a reasonable time. This belongs to the requirements of a fair trial under Article 6 ECHR (Capuano v. Italy).7 Passivity of the judge is considered to create backlogs and sluggish litigation. It would be interesting to investigate whether the emphasis on passivity is also problematic in Ukraine. Maybe this is not the case since ca. $56 \%$ of respondents are of the opinion that the passive role of the judge does not impact on the requirement of a hearing within a reasonable time. If this is indeed true, this is so surprising that the matter definitely deserves further attention.

\section{Question 41: Direct Oral Judgments}

41. Would a system allowing judges to pronounce judgment orally directly at the closure of the hearing, if properly recorded, be advisable in relatively uncomplicated cases?

A minority of respondents are against such an innovation (ca. $45 \%$ ), whereas a majority of respondents (ca. 50\%) are in favour (73\% of judges are in favour and only $41 \%$ of attorneys). Research in the Netherlands has shown that the approach suggested in the question increases efficiency and does not influence the quality of judgments since judges will only use this approach in relatively uncomplicated, small cases which do not need lengthy investigation (and after an oral hearing) and where the reasoning can be dictated immediately by the judge and recorded by the clerk. Such an approach also requires determined and skilled judges who aim at handling cases according to their complexity and merits. Moreover, this is only the case as long as indeed this practice is limited to simple and straightforward cases; one should avoid pressure to act likewise in more complicated cases as experience shows that in such situations mistakes are made. It might be advisable to show Ukrainian judges the implications of the Dutch approach in training sessions, allowing them to discuss it in an informed manner to allow them to determine whether this approach would suit Ukrainian legal culture.

\section{Chapter 4: Procedure}

\section{Questions 42 and 43: Taking Evidence}

42. What effect do the new obligations of the parties in the taking of evidence have as regards the determination of the case?

\section{Is it necessary to further specify the obligations of the court in the taking of evidence?}

Ca. $71 \%$ of respondents noted a positive effect of the new obligations of the parties in the taking of evidence, the majority of them being judges. This may not be surprising because the new rules shift much of the work in the evidentiary stage from the judge to the parties. This will indeed save time for judges, allowing them to pay attention to other matters and to reduce the backlog of cases. Ca. $63 \%$ of respondents also feel that the obligations of the courts in the taking of evidence need to be further specified. This most likely means that courts have different opinions of their role during the evidentiary stage of litigation and that rules are needed for uniformity. Drafting and introducing procedural guidelines, describing what the participants in civil procedure may expect from each other, can provide useful guidance. In this respect the Dutch project, initiated in the courts in Odessa and implemented by Judge Esther de Rooij (Amsterdam) (see above), deserves support and close attention.

\section{Question 44: Disclosure of Evidence}

44. Disclosure of evidence obliges the parties to produce documents that meet a certain standard of relevance spontaneously, even if not asked for by the opponent party and even if these documents are detrimental for their own case. Does the new obligation of disclosure of evidence have a positive effect? 
Disclosure is a tool from Anglo-American jurisdictions and is meant to compensate for the traditionally passive role of the judge in these jurisdictions. It is up till now to a large extent unknown in the civil law world. Where it concerns documentary discovery, it forces the parties to submit all relevant documents (including e-documents) to the court even if these documents are not beneficial for, or even detrimental to, their case. Ca. $54 \%$ of respondents believe that the new obligation has a positive effect, whereas ca. $32 \%$ do not believe there is a positive effect. Since discovery is a new tool that does not belong to the Ukrainian civil law tradition, it may be worthwhile to investigate how it works in practice. Often, lawyers who are unfamiliar with discovery, wrongfully think that it only forces the parties to provide relevant documents in an early stage of litigation, stimulating a cards-on-the-table approach. It is often forgotten that discovery also means producing documents that may be detrimental for one's own case and being sanctioned if this does not happen spontaneously. It furthermore means that the opponent party does not have to identify documents it wants to see that are in the possession of the other party and to ask the judge for their production (after all, these documents should have been produced spontaneously by the other party).

\section{Question 45: Is Disclosure Rightly Understood?}

45. Disclosure obliges the parties to produce documents that meet a certain standard of relevance spontaneously, even if not asked for by the opponent party and even if these documents are detrimental for their own case. Is disclosure understood rightly by the courts?

Ca. $48 \%$ of respondents answer this question positively, and ca. $39 \%$ negatively. Opinions are divided and this may be a reason to have a further look into the way this new procedural instrument works in practice in Ukraine.

\section{Question 46: Procedural Abuse}

46. Are judges in a position to prevent parties and their attorneys to apply the rules in the wrong manner?

Ca. $78 \%$ of respondents answer this question positively. It seems, therefore, that a large majority of respondents are of the opinion that the new Codes have given the judge the necessary tools to guard against procedural abuse. This is obviously very positive.

\section{Question 47: Delay}

47. Which instruments are used to prevent delay?

According to $56 \%$ of respondents, case calendars and hearings for directions are most often used in order to prevent delay. The respondents show that tools like consultations with the parties are not very often used. In light of the adversarial approach to litigation under the new rules, which do not put an emphasis on cooperation, this outcome is not a surprise since consultations belong to a more cooperative model and not to an adversarial model like the Ukrainian model. In international literature on civil procedure, consultations are, however, considered to be positive since they foster a cooperative model of litigation. The fact that Ukraine has introduced a model of litigation with many adversarial elements may hinder the use of consultations. This is not in line with the best international practices.

Question 48: Omitted as it was Interpreted in Different Ways by the Respondents.

Question 49: Facts on Appeal

49. How does the appellate court deal with the facts of the case? 
The situation does not seem straightforward since ca. $43 \%$ of respondents are of the opinion that only the facts provided at first instance are taken into consideration, whereas ca. $50 \%$ feel that new facts are also taken into consideration. It is interesting to break down the results: $29 \%$ of judges answer that only facts presented at first instance may be taken into consideration, and $70 \%$ of judges believe that courts of appeal accept facts beyond those presented in the first instance. The situation of attorneys is that $45 \%$ thinks the first option is correct, while $55 \%$ answers that the court of appeal considers new facts. Since the new rules are straightforward on this matter, the answers to this question may indicate that not all courts of appeal apply the new rules correctly. This is a matter of concern since the powers of the court of appeal as regards the facts directly impact on the functioning of the justice system and the first instance courts in particular, and even on the procedural attitude of the parties.

One must bear in mind that if the courts of appeal accept new facts this potentially interferes with the clear intentions of the legislator: the approach should be to focus on the assessment of the case at first instance and not to allow litigation on new matters. If courts of appeal easily accept new facts, this will encourage attorneys to litigate strategically, not putting all their cards-on-the-table at first instance. It goes without saying that such an approach leads to frequent appeals and an extended length of proceedings.

\section{Questions 50 and 51: Access to the Cassation Court}

50. Does limited access to the cassation court influence the capacity of this court to guarantee the uniform application of the law?

51. Would the introduction of access filters at the cassation court reduce the workload of this court, allowing it to concentrate on the uniform application of the law and the development of the law?

Ca. $56 \%$ of respondents answer the first question positively and ca. $40 \%$ negatively. This division of opinions is surprising, since it is generally recognised that unlimited access to the cassation court will result in an overburdened court that cannot execute its main task in the area of uniformity of practice and development of the law. A good example of such a dysfunctional, overburdened cassation court can be found in Italy (where access to the cassation court is a constitutional right, and this is wrong in the opinion of the experts). Consequently, most jurisdictions have introduced access filters to their superior court in order to keep the case load within limits, allowing the judges to investigate relevant cases seriously. It would therefore be important to study why a significant part of the respondents do not believe that limited access to the Supreme Court influences the capacity of the court to guarantee a uniform application of the law. This is especially true in light of the answers to the second question above. This question is answered positively by ca. $75 \%$ of respondents and negatively by ca. $20 \%$.

\section{Question 52: Court Fees and Access to Court}

52. Do court fees influence access to court?

Ca. $77 \%$ of respondents answer this question positively, as could be expected. In order to guarantee access to court, help needs to be provided to parties of limited means. This help, however, should only be provided in real cases, which means that a test as regards the merits of the case needs to be performed before legal aid is being granted or court fees are reduced or suspended. It should be remembered that court fees are also a means to make litigants think about the merits of their case before going to court and incurring expenses. Given the huge case load of the Ukrainian courts, one needs to ask whether the system of helping indigent parties to litigate contains sufficient safeguards against unmeritorious cases arriving at the court.

\section{Question 53: Flexibility in Procedure}

53. Do the present rules allow sufficient flexibility in allowing the judge to handle cases according to their specific features (i.e. allowing the judge to select the case-management techniques and mechanisms that do justice to the case at hand)? 
Ca. $48 \%$ of respondents answer this question positively and ca. $40 \%$ negatively. This means that a serious number of respondents feel that flexibility is lacking. A lack of flexibility was also the impression of the experts when consulting the Codes and when discussing matters with judges and lawyers. It seems that the rules prescribe a relatively rigid framework for handling cases, leaving the judges little discretion in this respect. The Codes provide a rather legalistic approach to matters without taking into consideration that cases may differ considerably, also from a procedural perspective. A one-size-fits-all (or three-sizes-fit-all) is often not the right solution to matters. The fact that ca. $40 \%$ of respondents feel that sufficient flexibility is absent justifies further attention. In the end, flexibility in handling cases in court is an important tool for effective, efficient, and high-quality litigation (and in the end, for access to justice).

For such an approach basic trust in the skills and abilities of judges is required. As stated above, such trust is low or even absent in Ukraine. It is essential that measures are taken to enhance trust in the judiciary. By creating an environment where judges are willing to use their skills and knowledge in an effective manner and by limiting the possibility to submit complaints against judges who do their work in a faithful manner, one might create a common understanding of how civil lawsuits are conducted in court which will be beneficial for all concerned.

\section{Question 54: Early Oral Hearing}

54. Can an oral hearing be scheduled in an early stage under the present rules?

Ca. $53 \%$ of respondents answer this question positively and ca. $35 \%$ negatively. This is surprising since the Codes should be clear in this respect. A closer look into this matter is needed, also since an early oral hearing appears to be a good instrument for increasing efficiency and quality.

\section{Question 55: Referral in Case of Lack of Jurisdiction}

55. To what extent will courts that not have jurisdiction automatically refer cases to the competent court?

Ca. $50 \%$ of respondents answer that such referrals occur always or mostly and ca. $27 \%$ that they occur rarely or never. Automatic referrals are important in light of access to justice, but also in light of efficiency and quality. Courts (and the procedural rules) should avoid or remedy jurisdictional problems as much as possible themselves. Jurisdictional complications should not or very rarely occur in a well-working justice system: they are systemic irritants. In addition, the experts feel that the rules on jurisdiction should not be so strict as to disallow the litigants a choice of court.

\section{Chapter 5: Settlement and ADR}

\section{Questions 56, 57 and 58: Settlement}

56. Should measures be taken to enhance early settlement?

57. To what extent does early settlement occur in practice?

58. In which stage of the proceedings does early settlement occur in practice?

Ca. $88 \%$ of respondents answer the first question positively. Settlements are instruments to avoid costs for the parties and alleviate the burden on the State judicial system. Many jurisdictions, therefore, stimulate settlement, especially in the early stages of the lawsuit. The experts learned that there are tools available in the Ukrainian legal system that are aimed at promoting settlement, but that these tools are often not used. An example of a tool that is rarely used is in-court settlement. The limited use of settlement techniques also appears from the answers to the second question above, where respondents indicate that early settlement does not often occur in practice. If settlement occurs, often it occurs only after the hearing or even in the final stages of the case. It is, therefore, not a surprise that the respondents feel that measures should be taken to enhance early settlement.

One of the areas in which early settlements prove to be of great value are divorce and family law cases. From a legal perspective these are often relatively simple cases, but at the same time they 
are factually and emotionally complicated cases. Early settlement (wholly or in part) in these cases is clearly in the interest of the parties and their family. The way settlement is regulated in divorce and family cases in Ukraine may not be the most effective way. Ukrainian judges are allowed to mediate between the parties to reach a settlement. However, this means that if mediation is unsuccessful, the case needs to be transferred to another judge for reasons of impartiality (Art. 205(4) CPC). This may not be efficient and one could ask whether judges should not use other techniques to reach a settlement, techniques that do not require the transfer of the case to another judge in case of failure.

Experience in other jurisdictions shows that the judge can try to have parties reach a friendly settlement without using mediation techniques that disqualify them from hearing the case in case of no-settlement due to a possible violation of impartiality principles. Judges may, for example, order a hearing in which they discuss the case with the parties and their lawyers. This would illustrate the various possible scenarios and give the parties some time to discuss matters amongst themselves to see whether on the basis of the information provided by the judge a settlement is possible. Judges may also ask the parties whether they would be willing to use out-of-court mediation before a private mediator since a mediated settlement is often better for the future relationship of the parties than a court decision. The introduction of court-annexed mediation could also be considered. In that case, parties could be referred to a court-approved external mediator while the court adjourns the hearing. In case mediation is successful, the court will close the case, if necessary, by incorporating the agreement reached in a judgment. If mediation is unsuccessful, the case will be continued before the same judge.

\section{Questions 59 and 60: $A D R$}

\section{Are ADR mechanisms often used?}

\section{Does the use of ADR mechanisms influence access to court?}

The final questions in the questionnaire concern the use of ADR (alternative dispute resolution), which can be defined as mechanisms to solve disputes without the help of the State judiciary. According to ca. $77 \%$ of respondents, they are not often used in Ukraine, even though ca. $41 \%$ of respondents feel that these mechanisms influence access to court (ca. 52\% of respondents believe that these mechanisms do not influence access to court). The experts feel that access to court is at stake in relation to ADR if one considers access to court from the perspective of the judicial system as a whole. Large numbers of litigants making use of the State judicial system influences access to court negatively since the means to finance the system are by definition limited. It is therefore important that litigants are empowered to solve their disputes as much as possible without the help of the state, and ADR provides a very useful instrument for this.

It should be noted that some respondents did not have a clear idea about the definition of ADR. Alternative dispute resolution by its very definition is a means of resolving disputes without the use of the State court system. Examples are:

- Arbitration (litigation before a private judge appointed by the parties);

- Mediation (settlement attempts before a neutral third party who does not decide but who facilitates settlement negotiations);

- Resolution of claims by consumer complaints boards; or

- Submission of a case to a neutral third party who issues a binding decision to which the parties have agreed to abide beforehand in a contract (this is called 'binding advice' in the Netherlands).

\section{SUMMARY}

Questionnaire A has allowed the experts to identify and define many issues in the application of the Ukrainian Civil and Commercial Procedural Codes. Part of these issues were problems in the application of the Codes. Furthermore, training seems to be problematic: the overwhelming majority of respondents are of the opinion that additional training is needed. Such training 
should, according to the respondents, take place within a stable procedural framework in the sense that the Codes should not be changed too often.

Respondents are generally satisfied with the level of orality of the procedure according to the new Procedural Codes. They are also satisfied with the role of case law, and they feel that the system of case reporting has a positive effect on the uniform application of the law throughout Ukraine. The majority of respondents are positive about the quality of the judgments of the Supreme Court as well, although there is no agreement as regards the status of these judgments in the Ukrainian legal system.

Procedural differentiation in the sense of tailoring the procedure to the type of case at hand works well according to the majority of respondents. Respondents are divided as regard the question whether sanctions against procedural misbehaviour are effective. The statement that mandatory representation by a lawyer increases the quality of the court decision is supported by a large number of respondents, whereas there is strong support for the statement that mandatory representation increases access to court. Mandatory representation also means, according to respondents, that cases are prepared well before they go to court. Respondents are divided about whether the new rules foster independence and impartiality of judges. Respondents seem equally divided as regards the trust to be given to judges when implementing the new rules of procedure loyally. They, nevertheless, seem to favour more active judges, since the majority of respondents think it to be a good idea to allow the court to give a neutral analysis of the case to the parties and in this manner, influence the way the case is litigated.

The respondents are divided about the question whether a passive role of the judge results in fair decisions, while there is also no clear majority in favour of the idea that a passive judge increases efficiency. A majority of respondents, and especially the judges, noted a positive effect of the new obligations of the parties in the taking of evidence. The respondents are divided about the question whether documentary discovery has positive effects. They are also divided about the way the appellate courts deal with the facts of the case. This difference of opinion is surprising since the new rules are straightforward on this matter. Respondents are even divided about the effects of unlimited access to the Supreme Court. This division of opinions is surprising as well, since it is generally recognised that unlimited access to the Supreme Court will result in an overburdened court that cannot execute its main tasks in the area of uniformity of practice and development of the law.

Finally, according to the majority of respondents, in-court settlement and ADR are not often used in Ukraine, even though a large proportion of respondents feel that settlements may lead to fast and positive results of procedures while ADR influences access to court.

\section{QUESTIONNAIRE B}

The in-depth-interviews with stakeholders on the basis of Questionnaire B were conducted to provide the necessary background information, and helped to identify additional areas in need of attention. The areas identified concern, amongst other things, the work conditions at the courts, the remuneration of judges, the staffing and size of the courts, judicial specialisation, the fact that judges perform many tasks unrelated to deciding disputes on the merits, judicial discretion, the introduction and implementation of new procedural rules, practice directions, allocation of cases, and the service of the summons (notification). 